Journal of the Scholarship of Teaching and Learning, Vol. 19, No. 4, October 2019, pp.1-17.

doi: 10.14434/josotl.v19i4.24158

\title{
Faculty Beliefs about the Nature of Intelligence
}

\author{
Lisa M. Rubin \\ Kansas State University \\ rubin@k-state.edu \\ Emily Dringenberg \\ Ohio State University \\ Jessica J. Lane \\ Kansas State University \\ Andrew J. Wefald \\ Kansas State University
}

\begin{abstract}
The purpose of this study was to measure the beliefs that faculty from various academic disciplines hold about both the nature of their own intelligence and the intelligence of their students. Faculty at one land grant institution participated in this pilot study, completing an eight-item mindset survey based on the work of Dweck $(2000,2006)$. Though several variables were studied (i.e., age range, position, rank, gender, college/academic discipline), only position was statistically significant for difference in beliefs between teaching and tenure-track faculty. Findings also show that faculty's beliefs about their own intelligence and the intelligence of their students are consistent. These results suggest that tenure-track faculty should engage with teaching faculty, focusing on creating a studentcentered learning environment to empower students through a growth mindset in their classrooms.
\end{abstract}

Keywords: Mindset, Intelligence, Faculty Beliefs, College Learning Environment, College Teaching

Higher education serves as an opportunity to liberate and empower students, as colleges and universities provide an environment for students to learn and become more educated citizens. Students seek higher education to develop skills and ways of thinking that can launch careers and provide security through employment. Ultimately, higher education can provide a gateway for lifelong learning. In order to gain such liberating outcomes, individuals who pursue higher education need to experience learning environments that convey the power of learning and personal growth. The undergraduate experience is extremely formative for many individuals who invest in post-secondary education. While there are many ways in which student development is facilitated throughout their college experience, a major factor in students' development is their time spent in the classroom in learning environments controlled by faculty members. Students learn how to manage their time, achieve goals, think critically, develop interpersonal skills, and work in teams. Tinto (2012) argued that institutions must focus on the educational experience that college students have in the classroom, especially amongst first-year students to positively impact retention. One major contribution to students' academic empowerment is the learning environments that faculty create in classrooms. Educators can shape the learning experiences of students in the classroom in ways that stretch beyond their content expertise to include implicit beliefs about the deeper purpose and impact of learning.

According to Association for Institutional Research (2017), the retention rate at the large, public institution where this study was conducted is $85 \%$ retention from first to second year, but the six-year graduate rate is only $63 \%$. In other words, over a third of the individuals who show up seeking 
a college degree don't finish. For students whose family income is under $\$ 35,000$, the likelihood of graduating is just one in 17 (Selingo, 2018). Many variables are understood to influence retention; research has looked at aspects of student experiences such as motivation (see Vallerand et al., 1992), identity development (see Chickering \& Reisser, 1993), and student involvement (see Astin, 1984), and significant efforts are made to address these factors explicitly to improve retention. However, an additional factor, which is often left implicit, is an individual's beliefs about intelligence. The beliefs that an individual holds about intelligence, specifically whether intelligence static or malleable, has been shown to directly influence motivation, effort and persistence (Blackwell, Trzesniewski, \& Dweck, 2007; Dweck, 2000, 2006). Built on our assumption that higher education should serve as a platform for life-long learning to enable personal and professional success, we are interested in the beliefs that faculty hold about the nature of intelligence. These beliefs are important because postsecondary educators have the power to shape students' learning experiences in ways that influence the students' own beliefs, which are linked to their retention and persistence toward graduation.

At the university level, faculty hold particular beliefs about the nature of intelligence, and these beliefs can impact the experience of undergraduate students in a way that often remains unseen. For example, the beliefs about the nature of intelligence held by faculty can influence the beliefs students have about their own intelligence and abilities to learn and perform academically. Faculty members are in positions of power, and their beliefs about the nature of intelligence are often implicitly transferred to students. In general, Western societies convey intelligence as something that is an inherent individual difference (Rattan, Savani, Naidu, \& Dweck, 2012). Students see their professors as experts or geniuses in the field (Blair, Tolman, Krelming, \& Morris, 2016), and an expectation that a given field requires innate brilliance predicts lower participation of women and underrepresented minorities (Leslie, Cimpian, Meyer, \& Freeland, 2015). What sort of culture might undergraduates experience as a result of their interactions with faculty? Astin (2016) cautioned, "The faculty culture regards smartness in an almost reverential fashion" (p. 4). Obsession with intelligence levels, and a belief that intelligence is something you either have or you don't, represents the fixed mindset in Dweck's (2006) mindset framework. This pilot study is a critical first step for a longer-term goal of better understanding how the beliefs of educators, who are people in positions of power, can impact their students' beliefs about the nature of intelligence.

\section{Literature Review and Theoretical Framework}

In order to investigate the construct of beliefs about the nature of intelligence, we utilized Dweck's (2006) mindset framework, which includes a simple self-report assessment to measure one's beliefs. Developed in educational psychology, this framework focuses just on the beliefs that individuals hold, without being able to capture the larger context or culture that contributed to the development or reinforcement of these beliefs. Despite this limitation, the framework is useful because it is well established and supported by substantial empirical research. In this section, we introduce the mindset framework, followed by a review of relevant literature, which informed our formation and investigation of the posed research questions.

\section{Theoretical Framework: Mindset}

Mindset is a framework for beliefs about the nature of intelligence developed by Dweck (2000, 2006). This framework focuses on the implicit beliefs about the nature of on intelligence, which have been shown empirically to inform one's motivation, effort, and persistence in the face of challenges (Blackwell, Trzesniewski, \& Dweck, 2007; Dweck, 2006). More specifically, the framework separates the beliefs that a given individual holds about the nature of intelligence into two divergent categories:

Journal of the Scholarship of Teaching and Learning, Vol. 19, No. 4, October 2019.

josotl.indiana.edu 
intelligence as a static characteristic inherent to an individual (fixed mindset), or intelligence as malleable and increased with effort (growth mindset) (Dweck, 2006). The fixed mindset is a belief system that operates on the assumption that intelligence is, by nature, static and fixed within an individual. According to Dweck (2000), those who believe their intelligence is fixed think that "they have a certain amount of it and that's that" (p. 2). This mindset is also referred to as "an 'entity theory' of intelligence because intelligence is portrayed as an entity that dwells within us and that we can't change" (p. 2). Research has shown that those with a fixed mindset are more likely to engage in the following behaviors: fear being wrong, focus only on final results, blame external sources for failure, believe that effort is fruitless and a sign of low ability, recognize "natural ability," and give up when faced with adversity (Dweck, 2006, p. 47). Individuals with a fixed mindset are motivated by performance goals that validate their intelligence because they can do them easily and project an image of effortless competence (Dweck, 2000). The behaviors linked to fixed mindset are not indicative of individuals who will persist in higher education and become life-long learners, threatening retention.

In contrast, individuals with a growth mindset believe that intellectual abilities can change (Dweck, 2006). Those with a growth mindset believe that intelligence is something "they can cultivate through learning" (Dweck, 2000, p. 3). This belief is central to academic achievement and productive learning attitudes. According to Dweck (2000), "The hallmark of successful individuals is that they love learning, they seek challenges, they value effort, and they persist in the face of obstacles" (p. 1). Dweck (2000) called this “an 'incremental theory' of intelligence because intelligence is portrayed as something that can be increased through one's efforts" (p. 3). This set of beliefs about the nature of intelligence is likely to be correlated with presence of the following behaviors: accept challenges, focus on improvement along the way, take responsibility for learning and performance, value hard work, practice grit and mental toughness, and persist despite adversity. In summary, people with a growth mindset are motivated by the desire to learn rather than a desire to look smart (Blackwell et al., 2007; Dweck, 2000).

Mindset research has focused on a wide range of ages, from P-12 students to college students as well as teachers in P-12 settings (Dweck, 2000; Dweck, 2006; Yeager \& Dweck, 2012). For example, research has shown that middle school students who adopt a growth mindset exhibit positive efforts and strategies toward more learning goals and see improvement in academic achievement (Blackwell, Trzesniewski, \& Dweck, 2007). Though to focus of mindset research has been on students, some of the most concrete findings from research in this area have included the important role of how learning is facilitated, by parents or by educators. Blair et al. (2016) shared ways in which promoting student metacognition might change students' mindsets towards a growth mindset. They suggested that professors admit their academic struggles and failures to students, to show them that "the struggle to grasp complex material is a normal part of learning" (p. 183). However, there is a gap in the literature specifically focusing on the beliefs about intelligence held by faculty in higher education, so this study aims to extend the body of knowledge by assessing these beliefs with a different audience-faculty at a large university.

\section{Students' Beliefs Affect Achievement}

The beliefs that student hold about the nature of intelligence have strong, research-based links to their behavior, achievement, and persistence. When presented with hypothetical major academic setbacks, students with a fixed mindset blamed their own lack of intellectual ability while students with a growth mindset focused on the needs for new strategies or heightened effort (Blackwell et al., 2007; Zhao, Dweck, \& Mueller, 1994). Undergraduate pre-med students are more likely to persist despite their initial grades in chemistry if they possess a growth mindset (Dweck, 2006). Adopting a growth mindset

Journal of the Scholarship of Teaching and Learning, Vol. 19, No. 4, October 2019. josotl.indiana.edu 
has been shown to reduce the effect of stereotype threat, which can impair achievement, in college students from marginalized groups (Aronson, Fried, \& Good., 2002).

Beliefs about the nature of intelligence also impact the behavior and motivation for learning of younger students. Fifth graders who take more responsibility for their intellectual achievement are more likely to persist despite prolonged failure (Dweck \& Reppucci, 1973). Training on growth mindset improved the math grades of a diverse group of 7th graders (Blackwell et al., 2007). This type of belief has even shown to be predictive of adult behavior. When brain activity was recorded, adults with a fixed mindset were found to pay attention just to positive feedback, while adults with a growth mindset demonstrated brain activity when they were given constructive criticism-individuals with growth mindset were focused on learning, not just being right (Dweck, 2006). Across this range of studies, a significant amount of evidence identifies Dweck's theory of growth mindset as a critical framework for motivation and learning.

\section{How Teachers' Beliefs Affect Student Learning}

In addition to the beliefs that students hold about the nature of intelligence being important for their learning, the beliefs that their teachers hold can also inform students' learning. Tinto (2012) emphasized that students' self-expectations are influenced by expectations of faculty in the classroom. According to Tinto (2012), "High expectations are a condition for student success, low expectations a harbinger of failure. Simply put, no one rises to low expectations" (p. 7). Prior researchers have demonstrated that teacher beliefs, even when implicit, influence students' own beliefs (Rosenthal \& Jacobson, 1968). More specifically, Rosenthal and Jacobson's (1968) study on teachers' expectations showed that "when teachers expected that certain children would show greater intellectual development, those children did show greater intellectual development" (p. 20). Teachers' beliefs are very powerful because students' mindset (fixed or growth) is linked to how their teachers and instructors view them (Dweck, 2006; Rubie-Davies, Hattie, \& Hamilton, 2006). For example, research (e.g., Dweck, 2006; Rubie-Davies et al., 2006) has shown that educators who focused on student growth and improvement created a powerful change; their teaching eliminated group differences when students were organized into groups by ability. In addition, Midgley, Feldlaufer, and Eccles (1989) studied how teacher efficacy impacted students' performance in math from the sixth to seventh grade year, retaining the same math teacher. They found that "the most efficacious teachers had higher expectancies and perceptions of [students'] performance in math than did students with less efficacious teachers" (p. 254). More specifically, they determined "a consistent relationship between teachers' beliefs about their personal efficacy and students' beliefs about their performance and potential in mathematics" (Midgley et al., 1989, p. 254). The researchers attribute changes in students' beliefs to their teachers' beliefs in them, and also discovered that teacher "beliefs have a stronger impact on low-achieving" students (Midgley et al., 1989, p. 256). This is especially important as we consider the struggles of marginalized groups.

Dweck (2006) suggested that lowering standards can lead to students who are poorly educated with a sense of entitlement to praise and simplistic work, which negatively impacts their learning. Based on Dweck's studies, teachers with a fixed mindset may categorize students, lowering expectations for those who they believe are less intelligent, while focusing more attention on developing students who they believe are smart. Considering the effects that teachers' expectations and mindset have on students, Tomlinson (1992) suggested that educators might offer students an easy way out rather than challenge them in the classroom. Instead, they must focus on the connections between educator beliefs and student learning (Tomlinson, 1992). Establishing a classroom that motivates students to support each other and to inspire them to love learning can have a significant impact on every student individually (Krumboltz, 2009). Dweck (2006) reminds educators that “...we

Journal of the Scholarship of Teaching and Learning, Vol. 19, No. 4, October 2019. josotl.indiana.edu 
are entrusted with people's lives" and that using the "growth mindset has a key role to play in helping us fulfill our mission and helping them fulfill their potential" (p. 204).

Additional research provides more concrete evidence that educators have the power to influence their students through their expectations. A chemistry professor at the University of Texas at Austin developed a separate general chemistry course for students from first-generation and/or low-income backgrounds, or low incoming SAT scores, and with encouragement to these students regarding their ability to be collegiate scholars, smaller class sizes, and peer mentoring, these students succeeded in the classroom and improved their learning (Selingo, 2018). Their achievements were a major improvement from previous semesters, when students with these backgrounds struggled to pass the course (Selingo, 2018). These outcomes demonstrate the power of one faculty members' beliefs in students' intelligence, despite their backgrounds or perceived abilities.

These contributions of previous research demonstrate that the beliefs and actions of educators can directly impact the beliefs and behaviors of students in ways that may be supportive of or detrimental to their academic achievement. Ultimately, teachers who believe their students' intelligence is fixed can hinder students' learning and academic development. Not only do students need a growth mindset to be productive (put forth effort), but educators also need a growth mindset about their students' intelligence to best facilitate their learning (Dweck, 2015). Therefore, it is important to build on our understanding of the power of intelligence beliefs of learners by exploring the intelligence beliefs of educators. A better understanding of the beliefs that faculty hold with respect to the nature of intelligence can ultimately be leveraged to empower students.

In summary, extant literature has identified the critical role of Dweck's mindset theory in students' approaches to learning and academic outcomes, such as retention. Faculty beliefs are also important to study because of the influence their beliefs have on their students' beliefs and learning. To build on these two premises, in combination with the majority of mindset research focusing on the beliefs of students, the goal of this study was to capture the beliefs of faculty in higher education. Specifically, we examined differences in faculty perceptions of their own intelligence and the intelligence of their students based on demographic and profile characteristics (i.e., age range, position, rank, gender, college/academic discipline). The purpose of this pilot study was to measure the beliefs that faculty from various academic disciplines across a large, public, land grant university (RU-VH classification) hold about the nature of their own intelligence and the intelligence of their students. With the extant literature's focus on children and P-12 education, we are expanding the body of knowledge by assessing faculty beliefs in higher education.

\section{Research Questions}

Our overarching research question is "What do faculty believe about the nature of intelligence?" This study is guided by the following research questions: 1) Do faculty perceive their own intelligence differently than that of their students? 2) Are there differences in how faculty perceive their own intelligence considering different demographic and profile characteristics? 3) Are there differences in how faculty perceive the intelligence of their students considering different demographic and profile characteristics?

\section{Methodology}

\section{Instrument Selection and Development}

This pilot study was designed to capture the landscape of faculty beliefs at a single institution through a pilot study. Leon, Davis, and Kraemer (2011) emphasized, "The primary role of a pilot study is to 
examine the feasibility of a research endeavor" and is not meant to highlight statistical power or complex outcomes (p. 628). Instead, a pilot study, with a smaller sample size and/or limited data source, is "a necessary first step in exploring novel interventions and novel applications of interventions" to help plan and design a larger study (p. 629). The survey utilized is a simple assessment of a person's orientation toward a growth or fixed mindset about intelligence (Dweck, 2006, p. 12). This assessment was selected because it is based on the mindset framework utilized for this study and was developed by the pioneer of this theory (Dweck, 2000; 2006). Specifically, we utilized the most recently published four items:

1. My intelligence is something very basic about me that I can't change very much.

2. No matter how much intelligence I have, I can always change it quite a bit.

3. I can learn new things, but I can't really change how intelligent I am.

4. I can always substantially change how intelligent I am. (Dweck, 2006, p. 12)

These four items assess faculty perceptions about their own intelligence. To assess perceptions of their students' intelligence, the four original instrument items were modified to replace "my" with "my students" and "me" with "they." As a result, we added the following four additional items to our instrument:

5. My students' intelligence is something very basic about them that they can't change very much.

6. No matter how much intelligence my students have, they can always change it quite a bit.

7. My students can learn new things, but they can't really change how intelligent they are.

8. My students can always substantially change how intelligent they are.

The original instrument (items 1-4) has been tested for validity and reliability by Dweck (2006) and in subsequent studies (e.g., Blackwell et al., 2007). Faculty responded to each of our eight items on a five-point Likert scale ("strongly disagree" to "strongly agree") and also provided their own demographic and profile information (i.e., age range, position, rank, gender, college/academic discipline). This study piloted the survey at one large, public, land grant university in the midwestern United States.

\section{Sampling}

In order to recruit participants from across the institution, the researchers contacted deans in each college and had the survey sent to faculty via college listserv e-mails in Fall 2016. Any faculty member who taught at least one class that semester was invited to participate, excluding graduate assistants. There were 1,630 faculty, both full-time and part-time, on the institution's campus in the 2017 fiscal year (Office of Planning \& Analysis, 2018). The participants $(n=212)$ comprised a response rate of 13\%. According to Fosnacht, Sarraf, Howe, and Peck (2017), "Surveys with small sampling frames need a relatively high response rate (20 to 25 percent) to be fairly confident in their survey estimates. In contrast, surveys with large sampling frames can obtain reliable estimates with lower response rates" (p. 259). Utilizing a sample size calculator, with our sample size, our margin of error is $6.28 \%$ with a confidence level of 88\% (Raosoft, 2017). 
Analysis

Statistical analysis of the survey results included producing descriptive statistics for each of the eight survey items and demographic data. The mindset items with negative wording (items 1, 3, 5, and 7) were reverse scored for analysis. The first four items of the survey, which assessed faculty members' individual mindsets, were aggregated to one composite variable for analysis, which represented the participants' mindset about the nature of their own intelligence (referred to as SELF). The last four items of the survey, which assessed faculty members' perceptions of their students' intelligence, were also aggregated to a separate composite variable for analysis (referred to as STUDENT). To address RQ1 (Do faculty perceive their own intelligence differently than that of their students?), the correlation between responses to questions about faculty intelligence and responses to questions about their students' intelligence were calculated to determine any differences. To answer RQ2 (Are there differences in how faculty perceive their own intelligence considering different demographic and profile characteristics?) and RQ 3 (Are there differences in how faculty perceive the intelligence of their students considering different demographic and profile characteristics?) we used one-way analysis of variance (ANOVA) to see if differences were significant between faculty by academic college, sex, position, rank, and age range.

\section{Results}

\section{Descriptives}

Based on the demographic and profile characteristics collected and summarized in Tables 1 and 2, survey participants included $46.8 \%$ males $(n=88), 51.6 \%$ females $(n=97)$, and $1.6 \%$ who preferred not to identify a sex $(n=3)$.

Table 1. Participant sample representation by age range

\begin{tabular}{|lll|}
\hline Age Range (years) & Count & Percent \\
\hline $25-34$ & 26 & $13.9 \%$ \\
$35-44$ & 58 & $31 \%$ \\
$45-54$ & 39 & $20.9 \%$ \\
$55-64$ & 44 & $23.5 \%$ \\
65 and older & 20 & $10.7 \%$ \\
Not reported & 1 & $0.01 \%$ \\
\hline Totals & 188 & $100 \%$ \\
\hline
\end{tabular}

Table 2. Participant sample representation by academic college

\begin{tabular}{|lll|}
\hline Academic College & Count & Percent \\
\hline Agriculture & 33 & $17.6 \%$ \\
Architecture & 13 & $6.9 \%$ \\
Arts \& Sciences & 9 & $4.8 \%$ \\
Business & 14 & $6.4 \%$ \\
Education & 24 & $12.8 \%$ \\
Engineering & 38 & $20.2 \%$ \\
Human Ecology & 37 & $19.7 \%$ \\
Veterinary Medicine & 19 & $10.7 \%$ \\
Information Technology & 1 & $0.5 \%$ \\
Totals & 188 & $100 \%$ \\
\hline
\end{tabular}


The participant sample representation by position is in Table 3. The Tenured and TenureTrack faculty were asked about academic rank separately from the Teaching Faculty and Clinical Faculty/Faculty of Practice based on the unique titles to this institution. The numbers in this pilot study are too small when broken down, and since rank was not a significant variable in this study, these results are not reported.

Table 3. Participant sample representation by position

\begin{tabular}{|lll|}
\hline Position & Count & Percent \\
\hline Tenured & 87 & $46.3 \%$ \\
Tenure-Track & 35 & $18.6 \%$ \\
Teaching Faculty & 52 & $27.7 \%$ \\
Clinical Faculty/Faculty of & 14 & $7.4 \%$ \\
$\begin{array}{l}\text { Practice } \\
\text { Totals }\end{array}$ & \\
\hline
\end{tabular}

The descriptive statistics, reliability coefficients, and intercorrelations for the variables are presented in Table 4.

Table 4. Means (M), standard deviations (SD), sample size (N), reliability coefficients, and intercorrelations

\begin{tabular}{|c|c|c|c|c|c|c|c|c|c|c|c|c|c|}
\hline & & M & $S D$ & $\mathrm{~N}$ & $\begin{array}{l}\text { Cronbach's } \\
\text { alpha }\end{array}$ & 1 & 2 & 3 & 4 & 5 & 6 & 7 & 8 \\
\hline 1 & Age & 3.88 & 1.27 & 188 & & - & & & & & & & \\
\hline 2 & Sex & 1.55 & 0.53 & 188 & & -0.09 & - & & & & & & \\
\hline 3 & College & 4.84 & 2.38 & 188 & & -0.01 & $.20^{* *}$ & - & & & & & \\
\hline 4 & Position & 1.96 & 1.02 & 188 & & $-.34 * *$ & $.22 * *$ & $.18^{*}$ & - & & & & \\
\hline 5 & Rank & 2.12 & 0.81 & 122 & & $.53 * *$ & $-.21 * *$ & .04 & $-.77 * *$ & - & & & \\
\hline 6 & Rank2 & 1.47 & 0.96 & 66 & & .22 & -.18 & .02 & .09 & - & - & & \\
\hline 7 & $\begin{array}{l}\text { Individual } \\
\text { Mindset }\end{array}$ & 3.23 & 1.11 & 194 & $\alpha=.91$ & .04 & .07 & .06 & $.15^{*}$ & .13 & .03 & - & \\
\hline 8 & $\begin{array}{l}\text { Student } \\
\text { Mindset }\end{array}$ & 3.28 & 1.16 & 188 & $\alpha=.95$ & .05 & .08 & .09 & $.15^{*}$ & .15 & .06 & $.96^{* *}$ & - \\
\hline
\end{tabular}

\section{Research Question 1}

The first research question asked, "Do faculty perceive their own intelligence differently than that of their students?" Overall, the survey responses about participants' own intelligence had a mean of 3.23 $(S D=1.11)$ and the responses about students' intelligence had a mean of $3.2793(S D=1.16)$. The correlation between the responses for these two measures resulted in a coefficient of $r=0.96$. Hence, the constructs appear to be almost the same since $r$ is so close to 1.00. Therefore, we can conclude that faculty do not perceive their own intelligence differently than that of their students.

\section{Research Questions 2 and 3}

The second research question asked, "Are there differences in how faculty perceive their own intelligence considering different demographic and profile characteristics?" The third question asked, "Are there differences in how faculty perceive the intelligence of their students considering different 
demographic and profile characteristics?" The data was submitted to an ANOVA with each demographic and profile characteristic as the independent variable and the two mindset composite scores, SELF and STUDENT as the dependent variables. For the variables of academic college, sex, rank, and age range, the results indicated that there were no significant differences between the variables' means and the responses to each of the mindset survey items.

However, for the variable of position, the data told a different story. The data was submitted to an ANOVA with position as the independent variable and SELF and STUDENT as the dependent variables. The four positions on the survey included Tenured, Tenure-Track, Teaching Faculty, and Clinical Faculty/Faculty of Practice. For SELF, the statistical test for position was significant, $F_{(3,184)}=5.01\left[M S_{e}=1.17\right], p<.05$. For STUDENT, the statistical test for position was significant, $F_{(3,184)}==5.08\left[M S_{e}=1.26\right], p<.05$. Both statistical tests showed a significant difference between position's means and the means for SELF and STUDENT. The ANOVA results are presented in Table 5. Graphs of the results are presented in Figure 1.

Table 5. ANOVA results

Faculty Rank (Assistant, Associate, Professor)

\begin{tabular}{|c|c|c|c|c|c|c|}
\hline & & Sum of Squares & df & Mean Square & $\mathrm{F}$ & Sig. \\
\hline \multirow[t]{3}{*}{ SELF } & Between Groups & 2.282 & 3 & .761 & .691 & .561 \\
\hline & Within Groups & 68.286 & 62 & 1.101 & & \\
\hline & Total & 70.568 & 65 & & & \\
\hline \multirow[t]{3}{*}{ STUDENT } & Between Groups & 1.638 & 3 & .546 & .495 & .687 \\
\hline & Within Groups & 68.378 & 62 & 1.103 & & \\
\hline & Total & 70.016 & 65 & & & \\
\hline \multicolumn{7}{|c|}{ Position (Tenured, Tenure-track, Teaching, Clinical/Practice) } \\
\hline & & Sum of Squares & df & Mean Square & $\mathrm{F}$ & Sig. \\
\hline \multirow[t]{3}{*}{ SELF } & Between Groups & 17.524 & 3 & 5.841 & 5.007 & .002 \\
\hline & Within Groups & 214.659 & 184 & 1.167 & & \\
\hline & Total & 232.184 & 187 & & & \\
\hline \multirow[t]{3}{*}{ STUDENT } & Between Groups & 19.104 & 3 & 6.368 & 5.075 & .002 \\
\hline & Within Groups & 230.860 & 184 & 1.255 & & \\
\hline & Total & 249.964 & 187 & & & \\
\hline \multicolumn{7}{|c|}{ Rank (Instructor, Advanced, Senior, Other) } \\
\hline & & Sum of Squares & df & Mean Square & $\mathrm{F}$ & Sig. \\
\hline \multirow[t]{3}{*}{ SELF } & Between Groups & 2.282 & 3 & .761 & .691 & .561 \\
\hline & Within Groups & 68.286 & 62 & 1.101 & & \\
\hline & Total & 70.568 & 65 & & & \\
\hline \multirow[t]{3}{*}{ STUDENT } & Between Groups & 1.638 & 3 & .546 & .495 & .687 \\
\hline & Within Groups & 68.378 & 62 & 1.103 & & \\
\hline & Total & 70.016 & 65 & & & \\
\hline
\end{tabular}

\section{College (Ag, Arch, A\&S, Bus, Ed, Eng, HE, Vet Med, Other)}

\begin{tabular}{lll|l|l|l|l} 
& & Sum of Squares & df & Mean Square & F & Sig. \\
\hline SELF & Between Groups & 12.092 & 8 & 1.512 & 1.229 & .284 \\
\cline { 2 - 8 } & Within Groups & 220.091 & 179 & 1.230 & & \\
\cline { 2 - 7 } & Total & 232.184 & 187 & & & \\
\hline & Between Groups & 13.902 & 8 & 1.738 & 1.318 & .237 \\
\hline & Within Groups & 236.062 & 179 & 1.319 & & \\
\hline
\end{tabular}




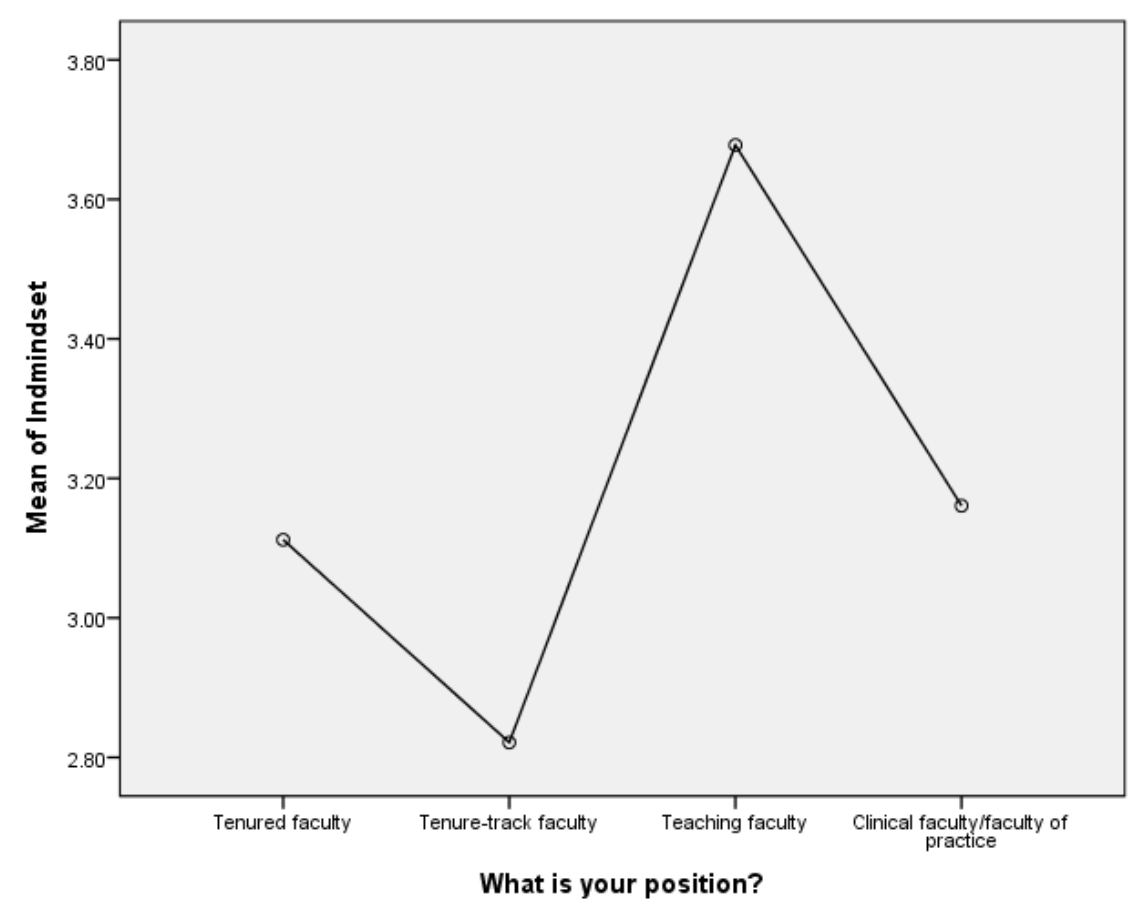

Figure 1. Graph of individual mindset (SELF) and faculty positions

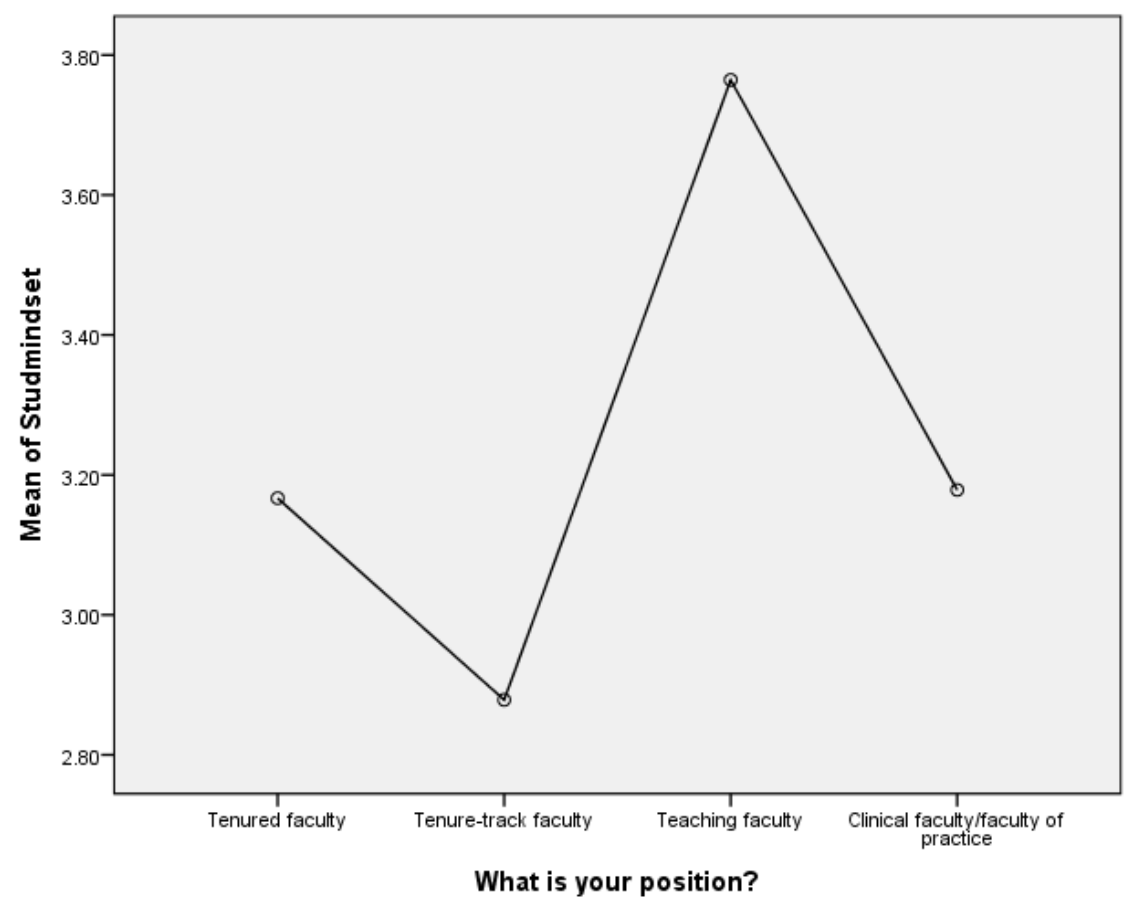

Figure 2. Graph of student mindset (STUDENT) and faculty positions

The results indicated that we should take a closer look at the differences between the responses of Tenure-Track $(n=35)$ and Teaching Faculty $(n=52)$. For RQ2, we calculated the aggregate means for perceptions of individual intelligence (SELF). Tenure-Track Faculty had a mean of 2.82 (SD=1.07) and Teaching Faculty had a mean of 3.68 (SD=1.03). For RQ3, we calculated the aggregate means for perceptions of student intelligence (STUDENT). Tenure-Track faculty had a mean of 2.88 
$(S D=1.12)$ and Teaching Faculty had a mean of $3.76(S D=0.99)$. The data was submitted to an ANOVA with position (Tenure-Track or Teaching Faculty) as the independent variable and responses to the SELF and STUDENT scores as the dependent variables. The statistical test for position (Tenure-Track or Teaching Faculty) was significant, $F_{(1,85)}=14.14\left[M S_{e}=1.09\right], p<.05$. Both tests show a significant difference between the specific positions' means and the means for individual and student mindset. These specific ANOVA results are presented in Table 6 and Figure 2.

Table 6. ANOVA results for tenure track (1) versus teaching faculty (2) ANOVA

SELF

\begin{tabular}{ll|l|l|l|l} 
& Sum of Squares & df & Mean Square & F & Sig. \\
\hline Between Groups & 15.345 & 1 & 15.345 & 14.141 & .000 \\
\hline Within Groups & 92.238 & 85 & 1.085 & & \\
\hline Total & 107.583 & 86 & & & \\
\hline ANOVA & & & &
\end{tabular}

\section{ANOVA}

STUDENT

\begin{tabular}{ll|l|l|l|l} 
& Sum of Squares & df & Mean Square & F & Sig. \\
\hline Between Groups & 16.416 & 1 & 16.416 & 15.049 & .000 \\
\hline Within Groups & 92.723 & 85 & 1.091 & & \\
\hline Total & 109.139 & 86 & & & \\
\hline
\end{tabular}

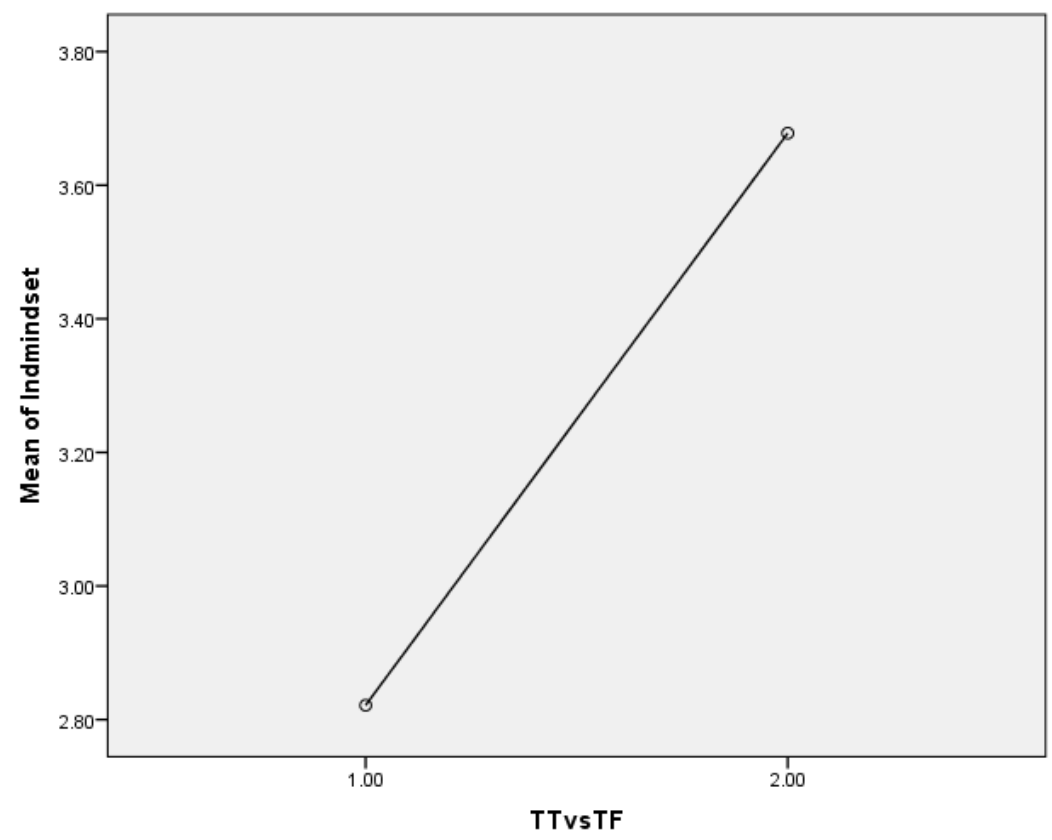

Figure 3. Graph of individual mindset and tenure track (TT) vs. teaching faculty (TF) 


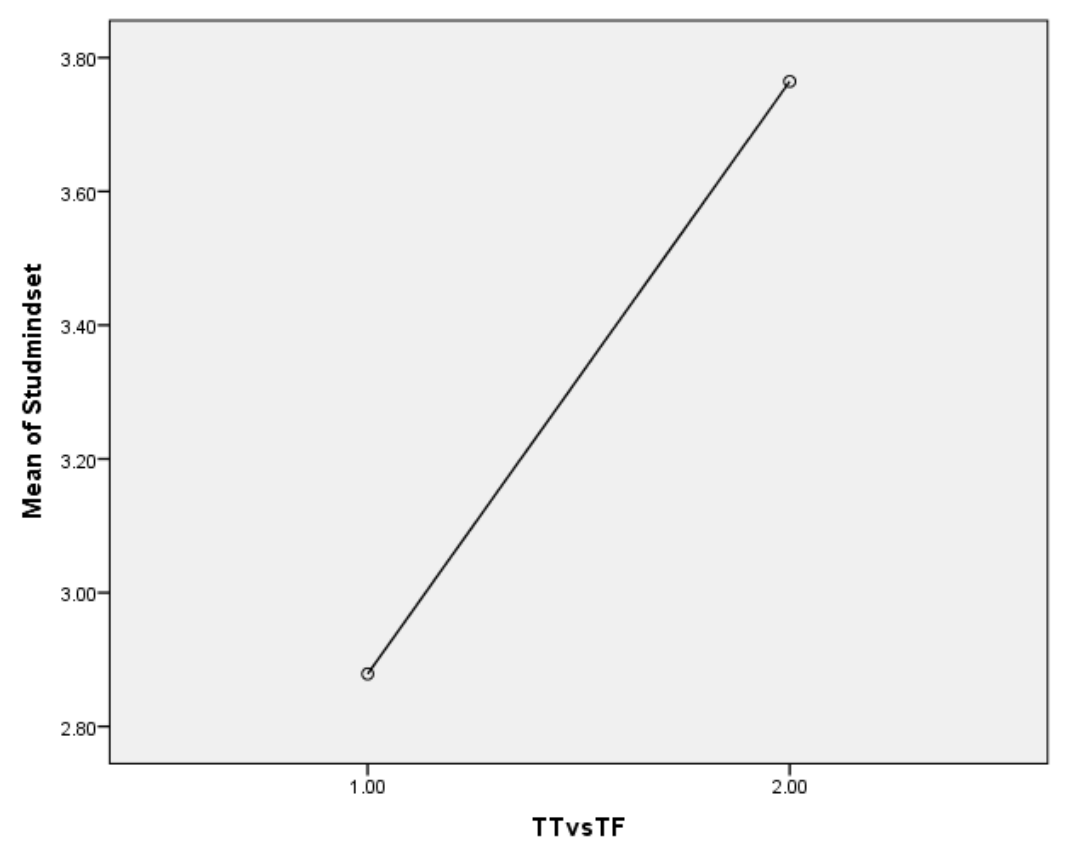

Figure 4. Graph of student mindset and tenure track (TT) vs. teaching faculty (TF) Note: Tenure Track $=1$, Teaching Faculty $=2$

\section{Discussion}

The overarching question that this pilot study aims to answer is "What do faculty believe about the nature of intelligence?" Using a simple survey with eight Mindset items and some demographic questions, 212 faculty across eight academic colleges at a large, Midwestern university responded. RQ1 asked, "Do faculty perceive their own intelligence differently than that of their students?" Based on the results, faculty perceived their own intelligence and that of their students with no statistically significant difference on the mindset items. We can conclude that faculty do not perceive their own intelligence differently than that of their students, which implies that beliefs about the nature of intelligence are held essentially constant between both self and others. This finding aligns with other research that suggests that intelligence beliefs remain stable over time (Robins \& Pals, 2002), but it contradicts more recent research that documents changes in intelligence beliefs during just a single year of college (Shively \& Ryan, 2013).

In our descriptive results, faculty tended toward growth mindset for perceptions of both their own intelligence and their students'. This is a positive result, but we cannot interpret too much from this finding. Dweck has cautioned that her mindset theory has been oversimplified (Dweck, 2015, 2016; Gross-Loh, 2016). She explained, "Everyone is a mixture of fixed and growth mindsets" (GrossLoh, 2016, para. 11). This is important to note since not everyone can be labeled as solely "fixed" or "growth," whether educators or students. Every faculty member and student is different, so it makes sense that we see results that hover around the mean on SELF and STUDENT scores. According to Dweck's theory, people can have growth mindsets toward some subjects and fixed mindsets toward others (Gross-Loh, 2016).

RQ2 asked, "Are there differences in how faculty perceive their own intelligence considering different demographic and profile characteristics?" and RQ3 asked, "Are there differences in how faculty perceive the intelligence of their students considering different demographic and profile characteristics?" The demographic and profile variables included age range, position, rank, gender, 
college/academic discipline. Through statistical analysis, we found that only position was a significant factor for differences in faculty perceptions of their own intelligence and the intelligence of their students. More specifically, there was a significant difference between Tenure-track and Teaching faculty; the other categories of Tenured Faculty and Clinical Faculty/Faculty of Practice were not significant.

This finding pushed us to return to the literature for prior work on differences between these two groups at the university level. Figlio, Schapiro, and Soter (2015) sought to determine if tenure track professors were better teachers than contingent (teaching) faculty, as they did not find much evidence in the literature that faculty status impacted "genuine student learning" (p. 715). They found the following outcomes for teaching faculty (especially in full-time positions) in comparison to tenuretrack faculty : they have a significant effect on student learning for any subject, regardless of grading standards or student qualifications for those subjects; they increased the number of students taking additional classes in their academic disciplines; and they inspired students to perform better academically in subsequent courses (Figlio et al., 2015).

For Tenure-Track and Teaching Faculty, the differences in the means for individual and student mindset show that the significant difference straddles "undecided" on the mindset scale. Tenure-Track Faculty tended toward a more fixed mindset (mean = 2.82) and Teaching Faculty tended toward a more growth mindset (mean $=3.68$ ). This was very surprising as we expected differences in other demographic factors, especially between academic disciplines. Related to our finding that some faculty tends towards beliefs that intelligence is fixed, we echo Astin's (2016) concern for faculty leaning toward fixed mindset:

Too many of the 1.5 million faculty members who staff our 4,000-plus institutions of higher learning have come to value merely being smart more than developing smartness! Developing students' talents is, after all, the principal mission of any educational institutions-to help students learn, grow, and develop into competent and responsible citizens, parents, employees, and professionals. (p. 1)

If educators fixate on test scores and letter grades, they might miss the opportunity to develop potential in all of their students, as Dweck (1999) suggested. McGuire and McGuire (2015) commented on their perception of why faculty may tend towards a fixed mindset:

One answer might be that all faculty were once students. We observed the blue, green, and yellow groups too. And we were usually put into the blue group. In order to let go of our fixed mindset, many of us must let go of the idea that we are smarter than the average bear. That can be a tough pill to swallow. Most of us also did very well in school. So when we have students who, for example, flunk our first two organic chemistry tests, what are we supposed to think? That those students are smart? (McGuire \& McGuire, 2015, p. 66)

Not every educator will share the same beliefs, regardless of position. However, for reasons suggested by both Astin (2016) and McGuire and McGuire (2015), faculty may struggle to adopt a growth mindset towards their students if they hold dear the intelligence they possess as fixed. Our findings spark our curiosity about broader constructions of what it means to be intelligent and the role that cultural norm influences beliefs. In other words, how might the cultural norm that research is somehow more prestigious than teaching relate to our finding that tenure-track faculty hold, on average, more fixed beliefs about intelligence than teaching faculty?

Based on the extant research reviewed in this paper, we do think that beliefs that intelligence is malleable are productive for students and faculty alike. To facilitate such beliefs, educators should 
make connections with students between their efforts and improvement in their academic abilities over time rather than using a single assessment to judge a student's potential for academic achievement. Dweck (1999) noted, "The fallacy is in thinking that by measuring someone's present skills, you've measured their potential; that by looking at what they can do now, you can predict what they're capable of doing in the future" (p. 59). Astin (2016) agreed, emphasizing, "Prediction, in short, doesn't necessarily have anything to do with learning" (p. 56). Educators should understand Dweck's idea that mindsets change over time. According to Dweck (2006), "You have a choice. Mindsets are just beliefs. They're powerful beliefs, but they're just something in your mind, and you can change your mind" (p. 10). However, developing growth mindsets in students in the classroom is not instantaneous, and there are larger societal and cultural norms that influence the beliefs that we hold.

Astin's (2016) primary concern is that we have created a culture in higher education that emphasizes "getting good grades" rather than "learning the subject matter" (p. 98) or that the focus on grades supersedes any need to actually learn or grow. To encourage a growth mindset, faculty can approach their classrooms by focusing on learning and designing courses to be more learning objective-based rather than grade-based. If educators emphasize the importance of utilizing a growth mindset approach, then their beliefs that their students can grow their intelligence through learning and effort may influence students' beliefs in their own abilities. Faculty's setting high expectations and reinforcing them can set students up for success which leads to increased retention and potentially higher graduation rates (Tinto, 2012).

\section{Significance}

Faculty members hold a lot of influence over their students in the classroom. For this study, we anticipated that academic discipline might be a factor in how faculty perceived the nature of intelligence in themselves and in their students (e.g., faculty in engineering might be more fixed mindset than faculty in education). However, results showed otherwise - there was a significant difference in beliefs about intelligence only between Tenure-Track and Teaching faculty at the pilot institution. Though Figlio et al. (2015) found similar results in their study at Northwestern University, further research is needed to examine how these positions differ and how that affects students beyond these two institutions.

\section{Limitations}

Because this is a pilot study, it only included faculty from eight academic colleges at one institution. Therefore, the results are not generalizable to other colleges. Though the sample size was robust for a pilot study, response numbers from some of the academic colleges were lower than others. With such a simple assessment, we have limited results for interpretation. A longer instrument may provide more robust results. We also did not include race as a variable in this study. Race is a very relevant factor, especially when considering the application of mindset as a framework. For our pilot study at a single institution, race coupled with the other demographic variables collected (especially rank, age range, and gender) would have shared enough information to identify participants. The institution publishes faculty demographics and each of the eight colleges have limited numbers of non-White faculty. Therefore, we prioritized the confidentiality of our participants over including race as an independent variable. 


\section{Future Directions \& Implications}

First, it would be valuable to replicate this study at other land grant institutions to increase sample size and add more variables for comparison. Since institutions do not necessarily have the same academic college names, groupings, or disciplines, that variable may need to be re-envisioned by discipline type (e.g., hard sciences, social sciences). We anticipated that other factors besides position would be statistically significant in this study, but that was not the case. We could conduct a follow-up study to examine further differences between Tenure-Track and Teaching Faculty in educational approaches and beliefs about intelligence. We are also interested in how students perceive their own intelligence, and how students feel their perceptions of their own intelligence are influenced by how they perceive their faculty and their faculty's mindsets.

Our results also prompt reflection based on the different cultures in higher education surrounding tenure-track faculty vs. teaching faculty. At our institution, research faculty also interact with students, so it may be of concern to understand how their tendency toward a fixed mindset impacts the learning experience of students in contrast to teaching faculty and their tendency toward a growth mindset. Another logical extension of this work is to research how to change the fixed mindsets of educators. We also think it is important to look beyond collecting survey data with a psychological lens to understand the role that culture plays in constructing smartness in higher education. For example, research could be aimed at determining if educator behaviors (e.g., instruction, grading, helping students) match their beliefs and mindset, and the role of these behaviors in student beliefs. According to Dweck (2015), "mindset isn't just about effort...Students need to try new strategies and seek help from others when they're stuck. They need this repertoire of approaches - not just effort - to learn and improve" (para. 5). Do students see that educators have a fixed or growth mindset? Is this something they can determine from how educators behave? Beliefs about the nature of intelligence are often not explicitly known and show up implicitly in teaching and learning environments.

Future research in this area could also look at college and university staff (e.g., academic advisors, student development professionals) to consider their mindsets. Surveying students' beliefs about the influence idealistic educators have on them would be another way to move towards understanding the impact of beliefs about the nature of intelligence. Ultimately, there are many possible future studies to determine how educators' beliefs may influence the learning and trajectories of college students.

\section{Implications}

The results of this pilot lead to several implications for higher education. First, faculty and staff should be encouraged to read Dweck's (2006) Mindset work and take the instrument to determine their SELF and STUDENT mindset scores. This is another tool to help educators understand their beliefs and practice as they can influence their students. Based on this pilot study's findings, the actual strategies used by teaching faculty (rather than of tenure-track faculty) in their classrooms with respect to fostering a growth mindset in students might be key to enhancing student learning and success in the classroom. As universities strive to provide quality learning experiences to all students, our results suggest there may be some opportunities for collaboration between faculty in different tracks. Institutions may consider a partnership between Tenure-Track and Teaching Faculty, for pedagogy idea sharing and teaching peer review or mentorship, especially given the findings of Figlio et al. (2015). In general, it may be a productive exercise to engage all faculty in explicit conversations focused on their beliefs about the nature of intelligence. These are opportunities for professional development and potentially enhancing approaches to teaching that may change Tenure-Track Faculty's mindsets 
from fixed to growth. When reviewing pedagogical practices, student-centered approaches should be considered.

\section{Conclusion}

This pilot study was a step in the direction of determining the power educators have to influence their students. Dweck's $(2000,2006)$ mindset theory provided a lens to consider how educators view the nature of their own intelligence and the intelligence of their students. By first looking at faculty, we can see how those who teach students in higher education may see intelligence through a fixed or growth mindset. Though several variables were studied (i.e., age range, position, rank, gender, college/academic discipline), only position was significant - Tenure Track and Teaching Faculty differed on the mindset scale for both the SELF and STUDENT scores. Tenure Track Faculty skewed more towards fixed mindset on both scales, and Teaching Faculty skewed more towards growth mindset on both scales. Another finding was that faculty beliefs for SELF and STUDENT were the same, which supports the idea that beliefs about the nature of intelligence are consistent. If a faculty member has a fixed mindset towards their own intelligence, it is likely the will have a fixed mindset about their students' intelligence. These results may shape changes in teaching approach to benefit college students in the future, as students should be empowered to learn and benefit from the advantages of obtaining advanced education.

\section{References}

Aronson, J., Fried, C.B., \& Good, C. (2002). Reducing the effects of stereotype threat on African American college students by shaping theories of intelligence. Journal of Experimental Social Psychology, 38, 113-125.

Association for Institutional Research. (2017). Common data set. Retrieved from http://www.commondataset.org/

Astin, A.W. (1984). Student involvement: A developmental theory for higher education. Journal of College Student Personnel, 25(4), 297-308.

Astin, A.W. (2016). Are you smart enough? How colleges' obsession with smartness shortchanges students. Sterling, VA: Stylus.

Blackwell, L.S., Trzeniewski, K.H., \& Dweck, C.S. (2007). Implicit theories of intelligence predict achievement across an adolescent transition: A longitudinal study and an intervention. Child Development, 78, 246-263.

Blair, R., Tolman, A.O., Kremling, J., \& Morris, T. (2016). How promoting student metacognition can reduce resistance. In A.O. Tolman \& J. Kremling (Eds.), Why students resist learning: A practical model for understanding and helping students (pp. 165-188). Sterling, VA: Stylus.

Chickering, A.W., \& Reisser, L. (1993). Education and identity. San Francisco, CA: Jossey-Bass.

Dweck, C.S. (1999). Self-theories: Their role in motivation, personality, and development. Philadelphia, PA: Psychology Press.

Dweck, C.S. (2006). Mindset: The new psychology of success. New York: Random House.

Dweck, C.S. (2015, September 22). Carol Dweck revisits the 'growth mindset.' Education Week. Retrieved from https://www.edweek.org/ew/articles/2015/09/23/carol-dweckrevisits-the-growth-mindset.html

Dweck, C. S. (2016, January 13). What having a "growth mindset" actually means. Harvard Business Review, 13. Retrieved from http:/ / thebusinessleadership.academy/wpcontent/uploads/2017/03/What-Having-a-Growth-Mindset-Means.pdf

Journal of the Scholarship of Teaching and Learning, Vol. 19, No. 4, October 2019.

josotl.indiana.edu 
Fosnacht, K., Sarraf, S., Howe, E., \& Peck, L.K. (2017). How important are high response rates for college surveys? The Review of Higher Education, 40(2), 245-265.

Gross-Loh, C. (2016, December 16). How praise became a consolation prize. The Atlantic. Retrieved from https://www.theatlantic.com/education/archive/2016/12/how-praisebecame-a-consolation-prize/510845/

Krumboltz, J. D. (2009). The happenstance learning theory. Journal of Career Assessment, 17(2), 135-154.

Leon, A.C., Davis, L.L., \& Kraemer, H.C. (2011). The role and interpretation of pilot studies in clinical research. Journal of Psychiatric Research, 45, 626-629.

Leslie, S. J., Cimpian, A., Meyer, M., \& Freeland, E. (2015). Expectations of brilliance underlie gender distributions across academic disciplines. Science, 347(6219), 262-265.

McGuire, S.Y., \& McGuire, S. (2015). Teach students how to learn: Strategies you can incorporate into any course to improve student metacognition, study skills, and motivation. Sterling, VA: Stylus.

Office of Planning \& Analysis. (2018). Fiscal year faculty and staff headcounts. Manhattan, KS: Kansas State University.

Raosoft. (2017). Sample size calculator. Retrieved from http://www.raosoft.com/samplesize.html

Rattan, A., Savani, K., Naidu, N., \& Dweck, C. S. (2012). Can everyone become highly intelligent? Cultural differences in and societal consequences of beliefs about the universal potential for intelligence. Journal of Personality and Social Psychology, 103(5), 787-803.

Robins, R. W., \& Pals, J. L. (2002). Implicit self-theories in the academic domain: Implications for goal orientation, attributions, affect, and self-esteem change. Self and Identity, 1(4), 313-336.

Rosenthal, R., \& Jacobson, L. (1968). Pygmalion in the classroom. The Urban Review, 3(1), $16-20$.

Rubie-Davies, C., Hattie, J., \& Hamilton, R. (2006). Expecting the best for students: Teacher expectations and academic outcomes. British Journal of Educational Psychology, 76(3), 429-444.

Selingo, J.J. (2018, June 11). Too many kids are dropping out of college - here's how to fix it. New York Post. Retrieved from https://utex.as/2JQ1a04

Shively, R. L., \& Ryan, C. S. (2013). Longitudinal changes in college math students' implicit theories of intelligence. Social Psychology of Education, 16(2), 241-256.

Tinto, V. (2012). Completing college: Rethinking institutional action. Chicago, IL: University of Chicago Press.

Vallerand, R.J., Pelletier, L.G., Blais, M.R., Briere, N.M., Senecal, C., \& Vallieres, E.F. (1992). The Academic motivation scale: A measure of intrinsic, extrinsic, and amotivation in education. Educational and Psychological Measurement, 52(4), 1003-1017.

Yeager, D.S., \& Dweck, C.S. (2012). Mindsets that promote resilience: When students believe that personal characteristics can be developed. Educational Psychologist, 47(4), 302-314. 